\title{
Existência Assistida: Uma etnografia do "ser" no Equador (Tradução)
}

Elizabeth F. S. Roberts*

\section{Resumo}

No Equador, a reprodução assistida, seja de Deus, da família extensa ou das tecnologias reprodutivas, é enfatizada como desejável num mundo precário e desigual, com uma rede mínima de segurança social e insegurança econômica crônica. Assistência é a própria base do existir. Em realidades com mais recursos, como parte dos Estados Unidos, as tecnologias de reprodução assistida podem modificar a autonomia individual, biológica e social de casais heterossexuais. Justapor a reprodução assistida em locais tão divergentes demonstra que recursos podem tornar a autonomia mais facilmente estabelecida e a assistência entre pessoas e coisas difícil de perceber. Através da insistência da especificidade de material da reprodução assistida, esses contrastes etnográficos contribuem para uma abordagem antropológica da questão ontológica do existir. Particularmente, a observação etnográfica das realidades materiais dos tratamentos reprodutivos no Equador demonstra que cuidados médicos são um meio de vislumbrar questões raciais. Serviços privados de reprodução assistida produzem bebês e pacientes mais brancos diante de um serviço desmantelado de saúde pública, cujos usuários são, por definição, pobres e indígenas. 0 quadro analítico de assistência pode ajudar a traçar etnograficamente a constituição de um ser racial em nações com melhores recursos, ao mesmo tempo que permite o reconhecimento compreensivo da interdependência da existência.

\section{Palavras-chave}

Equador. Sistemas de saúde. IVF. América Latina. Setor privado de saúde. Raça.

\section{Abstract}

In Ecuador, reproductive assistance, whether from God, extended family, or medical technologies, is emphasized and desirable in a precarious and unequal world with a minimal

\footnotetext{
${ }^{1}$ Artigo originalmente publicado no Journal of the Royal Anthropological Institute (2013) 19, 562 580, sob o título "Assisted existence: an ethnography of being in Ecuador". Todos os direitos são reservados ao Royal Anthropological Institute e foram cedidos para tradução e publicação na Revista Interseções. Agradecemos a Paulette Goldweber (Wiley Global) e Jessica Turner (RAI Publications) pela oportunidade.

* Professora Associada do Departamento de Antropologia da Universidade de Michigan. E-mail: lfsrob@umich.edu.
} 
social safety net and chronic economic insecurity. Assistance is the very grounds of being. In better-resourced realities like parts of the United States, assisted reproductive technologies can trouble the biological and social autonomy of individual heterosexual couples. Juxtaposing assisted reproduction in these divergent sites demonstrates that resources can make autonomy easier to establish and assistance between people and things difficult to perceive. Through an insistence on the material specificity of assisted reproduction itself, this ethnographic contrast contributes to anthropological approaches to ontological questions of being. In particular, ethnographic observation of the material realities of reproductive treatments in Ecuador demonstrates that medical care is one means to instantiate race. Private assisted reproduction makes whiter babies and patients in the face of a crumbling public health care infrastructure whose patients are by definition poor and Indian. The framework of assistance might serve then as a means to ethnographically trace the constitution of racial being in better-resourced nations, as well as allow for a more comprehensive recognition of the interdependence of existence

\section{Keywords}

Ecuador. Health care systems. IVF. Latin America. Private sector health care. Race.

\section{Introdução}

Profissionais da reprodução assistida de quase todas as nações das Américas Central e do Sul participaram, em 2003, da conferência da Rede LatinoAmericana de Reprodução Assistida (REDLARA). Um dos palestrantes foi a doutora Catherine Racowsky, uma reconhecida embriologista, diretora do laboratório e do programa de FIV do Hospital de Mulheres BRIGHAM em Cambridge, Massachusetts. Racowsky falou em vários painéis ao longo da conferência, sempre em inglês, com um marcado sotaque britânico. Muitos dos participantes, incluindo alguns dos médicos e biólogos de centros de reprodução assistida no Equador, onde eu estava conduzindo minha pesquisa na época, precisaram de tradução durante as suas falas. A performance da doutora Racowsky, como uma especialista em reprodução assistida do primeiro mundo, era deslumbrante. Ela era séria, e, ao mesmo tempo, apaixonada e intuitiva. Ao descrever seus protocolos específicos, ela explicou como "sente o que os embriões querem". Sua ênfase na precisão técnica e qualidade laboratorial foram preeminentes, mas isso não significa que ela imaginava que todos os laboratórios eram semelhantes. 
Durante as discussões sobre protocolos e técnicas, ela abordou como certas aproximações podem não funcionar em outros laboratórios por conta de diferenças na qualidade do ar, diferentes temperaturas, incubadoras e meios de cultura. Enquanto Racowsky reconheceu como diferentes condições laboratoriais podem emergir com equipamentos diferentes, sua recomendação como especialista, dirigida para médicos trabalhando na América Latina, não era capaz de compreender como clínicas podiam ter dificuldades em obter e manter equipamentos.

Os padrões laboratoriais com os quais Racowsky trabalha a permitem entendimento que toma como dado que todo equipamento e infraestrutura envolvidos na produção de resultados são encontrados em qualquer lugar. No entanto, a partir de minha pesquisa etnográfica em clínicas de FIV equatorianas, eu sabia que manter padrões laboratoriais precisos poderia ser extremamente desafiador. Atrasos alfandegários tornam difícil obter meios de cultura para embriões entregues sem danos ou medicamentos de infertilidade que não estejam prestes a expirar. Ciclos foram interrompidos por semanas em Quito, quando houve uma erupção vulcânica que contaminou a qualidade do ar nos laboratórios devido à falta de filtros. Comprar novos microscópios e incubadoras era uma tarefa extremamente desafiadora no Equador. Eles eram muito caros, difíceis de manter ou consertar. Certa vez, passei o dia inteiro com um biólogo em uma clínica de Quito, enquanto tentávamos resolver um problema com o fornecedor de um microscópio de micromanipulação. Nós não podíamos contatar ninguém para resolver o problema, e também não era possível ligar para o número gratuito da companhia.

Essas dificuldades afetavam as práticas clínicas de várias maneiras. Quando pipetas eram retidas nas alfândegas, os profissionais de saúde tinham de interromper as inseminações por um mês. Quando cateteres nem sequer chegavam, profissionais improvisavam os procedimentos com seringas comuns. Quando o laboratório ficava sem certos meios de cultura, eles tinham de transferir os embriões de volta para os pacientes no segundo, ao invés do terceiro dia, considerado o tempo ideal.

Essas dificuldades na manutenção clínica e laboratorial forneciam aos profissionais equatorianos um lembrete diário de quanta assistência a reprodução assistida necessitava para funcionar. Esses lembretes não eram nada além do cotidiano, dado que no Equador fazer as coisas, e fazê-las funcionar, sempre precisava de assistência. Isso incluía fazer novas pessoas, isto é, crianças, com ou sem reprodução assistida. Racowsky trabalhou e 
viveu em Cambridge, Massachusetts, onde a assistência necessária para coordenar a FIV, ou para criar crianças, é muito mais fácil de ignorar. O jeito como as coisas podem se unir com facilidade é parte e parcela de como as coisas são em geral, como pessoas e instituições podem parecer estáveis e autônomas. A relativa (e eu destaco relativa) estabilidade de estruturas, como escolas, saúde, estradas e saneamento público, em muitas partes dos Estados Unidos, pode produzir em pessoas de classe média e altas um senso de autonomia em relação a muitas de suas metas, incluindo ter filhos. Nesse terreno, a reprodução assistida pode ser sentida como uma imposição nessa autonomia.

Tive uma ampla experiência como etnógrafa da reprodução assistida - FIV, gestoras substitutas, doação de óvulos e esperma - primeiro, entre classes médias e altas na Califórnia dos anos 90, depois entre equatorianos urbanos de diferentes classes no começo dos anos 2000, durante um período neoliberal, prévio a tentativa de reformas sociais de Rafael Correa, incluindo a reforma do sistema de saúde (ROBERTS, 1998, 2012a). Através da observação etnográfica em ambos os lugares, notei que as experiências de reprodução assistida diferem entre, por um lado, Califórnia e, por outro lado, Quito e Guayaquil, as duas cidades onde as nove clínicas estavam situadas no momento da pesquisa. Essas diferenças foram, particularmente, causadas por papéis e variações situadas na "assistência" nessas, muito distintas, realidades materiais.

Nunca pensei muito sobrea "assistência" na reprodução assistida durante minha pesquisa na Califórnia dos anos 90. Assistência era um problema tão evidente que eu nunca pensei em analisá-lo. Assistência para superar a ausência de filhos entre casais heterossexuais assinalava que havia um mau funcionamento biológico em como as crianças devem, naturalmente, vir ao mundo. Equipamentos da FIV como cateteres, hormônios sintéticos e microscópios; a utilização de terceiros, como doadores de esperma, óvulos e gestoras substitutas; e esforços de profissionais, normalmente pareciam artificiais, intervenções externas em processos de reprodução biogenética, "naturais", que incluíam o ato sexual heterossexual, e o nascimento de crianças em famílias nucleares. Além de possivelmente alienar esses casais de suas experiências físicas naturais, a dependência da assistência tecnológica envolvia-os com pessoas e coisas indesejadas, colocando sua autonomia como casal em questão. Por exemplo, enquanto muitos casais que encontrei fizeram uso de doadores de gametas e gestoras substitutas, essas outras pessoas ameaçavam, potencialmente, a reivindicação da parentalidade 
exclusiva do casal. Embora eu tenha notado suas preocupações acerca da autonomia e artificialidade, naquele momento eu compreendia esses fenômenos como marcados de "especificidade" cultural. Não percebi como a relativa facilidade em coordenar as necessidades de suprimentos, doadores de gametas e dinheiro, nessas clínicas privadas, estava baseada na infraestrutura estatal que faz boas estradas, cadeias de abastecimento bem conectadas, uma abundância de pacientes educados, e uma relativa estabilidade em relação às instituições e pessoas. Eu não pensei muito a respeito da infraestrutura material que fez possível a FIV e também um senso idealizado de autonomia.

Nas áreas urbanas do Equador, descobri que aquelas ansiedades em relação à autonomia e artificialidade não se manifestam, nem de longe, no mesmo grau com que se manifestavam na Califórnia. A maioria das pessoas que encontrei nas clínicas de Quito e Guayaquil, muitos dos quais viajaram de pequenas cidades até lá, experienciavam a sua existência como fundamentalmente assistidas por outras pessoas, por Deus, e por uma série de outras coisas, todas as quais contribuíam para uma compreensão geral da reproducción assitida no Equador. A reprodução assistida não interfere com o sacrossanto ou natureza separada. Infertilidade heterossexual era um problema biológico, mas normalmente o problema maior estava no rompimento das relações que a ausência de filhos poderia trazer na continuidade da família estendida. Tecnologias de reprodução assistida poderiam trazer uma solução para esse rompimento através da assistência tecnológica, dinheiro e doadoras de óvulos.

Crucialmente, as aventuras reprodutivas nos centros urbanos do Equador não somente implicavam o fazer filhos, mas, também, fazer e reforçar as relações entre adultos, e entre adultos e Deus, em um mundo instável e materialmente inseguro. Meu trabalho de campo transcorreu em meio a um crônico e catastrófico ciclo econômico de inflação, devido ao crescimento e implosão do mercado petrolífero, bem como da dolarização e da ascensão e queda de nove presidentes em nove anos, dívida externa, fechamento de bancos, escândalos de corrupção, levantes indígenas, efeitos nefastos do racismo e constantes greves de servidores públicos, como professores, profissionais de saúde e polícia (CLARK; BECKER, 2007; GERLACH, 2003). Diante dessa instabilidade, a maioria das pessoas que encontrei no Equador, não importa quão vasta fosse seu acesso aos recursos materiais, experimentavam a vida como existencialmente precária e errática. A existência é então destacada não na autonomia individual, 
mas na necessidade de interdependência e conexão. Assistência é o próprio existir.

Desse modo, este artigo é sobre a importância da assistência na Reprodução Assistida em Quito e Guayaquil, com alguma justaposição com o que eu observei na Califórnia, para comparação. Contudo, é imperativo enfatizar que não há nada essencial sobre essas diferenças. A comparação é frágil devido a nossa tendência em ver diferenças como atemporais e fixas, e de modo ainda mais problemático, como surgindo separadamente - como se os processos históricos, econômicos, colonizadores e ambientais que moldaram a realidade de Quito não tivessem nenhuma conexão com os processos históricos, econômicos e ambientais que moldaram a realidade urbana de Deli, rural de Hunan ou dos subúrbios de Los Angeles. Ao fazer a justaposição da Reprodução Assistida no Equador com a Califórnia, não estou fazendo um modelo tipológico de norte/sul, centro/periferia para ser aplicado em outros locais. A Califórnia não está no "Oeste" ou "Norte". Por exemplo, no começo dos anos 1990, as clínicas californianas começaram a pagar pela doação de óvulos de doadoras conhecidas, algo incomum no resto dos Estados Unidos. Além disso, as infraestruturas do bem-estar social que faziam a vida parecer estável para pacientes de classe média com quem conversei na Califórnia eram muito diferentes das infraestruturas do bemestar social disponíveis na Grã-Bretanha, Espanha ou Leste Europeu, e essas nações eram diferentes uma das outras. A proibição da venda de óvulos na Grã-Bretanha produziu um efervescente mercado de óvulos na Espanha, onde essa prática era legal, preparado especificamente para cidadãos do Reino Unido. Registros etnográficos estão repletos de exemplos sobre como a reprodução assistida é praticada, especificamente dentro e entre nações, em relação às suas particularidades geopolíticas e histórias econômicas (BECK; KLOTZ; KNECHT, 2012; BHARADWAJ, 2002; M. CLARKE, 2009; FRANKLIN; ROBERTS, 2001; HANDWERKER, 1995; INHORN, 2003; IVRY, 2009; NAHMAN, 2008; PASHIGIAN, 2009; STRATHERN, 2005).

É muito importante enfatizar que as práticas de reprodução assistida no Equador também não são uniformes. Há diferenças na reprodução assistida em Quito e Guayaquil, relacionadas às especificidades regionais, econômicas e religiosas dessas duas cidades. Em Quito, que está localizada na sierra, um histórico de relações de produção agrária, patrão-cliente, produziu um sistema mais corporativo de trabalho e estrutura familiar, que também produz relações de troca mais materialistas e pessoais com Deus. Em contraste, na cidade portuária de Guayaquil, relações econômicas 
desde o século XIX têm sido estruturadas em torno da venda do trabalho individual (CLARK, 2002) e residentes tendem a ter uma relação doutrinária mais individual com Deus. Essas diferenças moldam práticas de fertilização in vitro, especialmente no que diz respeito a noções de pessoa e parentesco. Por exemplo, embriões e óvulos guayaquileños são mais individualizados do que embriões e óvulos quiteños, mas, em ambas as cidades, a reprodução assistida da nação implica reconsiderações da natureza e do parentesco, diferentemente do que ocorreu quando essas técnicas chegaram à Califórnia. Essa diferença pode ser explicada por uma percepção de que a natureza e o parentesco na sociedade urbana no Equador não estão baseados em uma separação ou relação de autonomia. Ao invés disso, a reprodução assistida reforça a assistência necessária para viver.

Meu argumento através deste artigo é materialista no que diz respeito ao que os recursos fazem quando aplicados em questões ontológicas sobre como pessoas vêm a existir. Óvulos de fertilização in vitro, embriões e pacientes são produzidos diferentemente na Califórnia, em Quito e em Guayaquil. No contexto californiano do início dos anos 90, fontes de equipamento e materiais eram confiáveis, tornando fácil estabelecer rotinas e protocolos regulares. Nesse contexto, o corpo das mulheres e os gametas produzidos, interna e externamente, eram tratados sob um regime relativamente estável de cuidado e infraestruturas alcançáveis, que não eram fáceis de serem percebidos. A autonomia era mais facilmente estabelecida, e a assistência era menos importante. Em outras palavras, recursos são "caixas pretas" que podem fazer a assistência entre as pessoas e coisas difícil de perceber. $\mathrm{Na}$ realidade menos estruturada de Quito e Guayaquil, a existência autônoma de qualquer coisa, sejam indivíduos biológicos, óvulos ou embriões, eram muito difíceis de estabelecer. Pessoas e coisas eram claramente transformadas e alteradas através de recursos, e, como descreverei em seguida, também eram alteradas características, como a raça.

\section{Realidade Maleável}

O modo de assistência à existência que encontrei nas áreas urbanas do Equador ressoa com o trabalho de teorias feministas, filosóficas, históricas, sociológicas e antropológicas da ciência, que defendem uma profunda interconectividade material do mundo, propondo termos como "biologias locais" (LOCKE, 1993), "natureza/cultura (HARAWAY, 1991)", e "biossociabilidades" (RABINOW, 1996). Esses acadêmicos insistem 
que cachorros, humanos, bombas de água, abelhas, terra, moluscos, computadores, legisladores, tomates, micro-organismos e divindades fazem-se, mutuamente, dentro de relações muito materiais (CALLON, 1989; DE LAET; MOL, 2000; HARAWAY, 2008; KOSEK, 2010; LATOUR, 1987; 2010; MOORE; KOSEK; PANDIAN, 2003; RABINOW, 1996). No mesmo caminho, a filósofa da medicina, Annemarie Mol, argumenta que objetos como doenças, corpos e estatísticas existem através da repetição de certas práticas e outros objetos que os mantêm no lugar - assim, a doença é diferente em um laboratório de patologia com o microscópio em comparação com um quarto de operação com um bisturi. O que atua em um objeto o faz, nas palavras de Mol, "ser é estar relacionado" (MOL, 2002, p.54).

O estabelecimento de uma doença, ou de um fato, ou ainda de uma pessoa, é realizado através de uma "co-ordenação", o processo de juntar a "diversidade de objetos que são chamados por um nome singular" (MOL, 2002, p.84). O que encontrei no Equador foi que o trabalho central de acadêmicos da medicina, ciência e tecnologia em lugares estruturados, o trabalho de notar todos os complicados atos de coordenação necessários para estabelecer objetos, pessoas ou fatos (CLARKE; FUJIMURA 1992; MOL, 2002), é algo que no Equador as pessoas experienciam diariamente. No Equador, colocar juntos a diversidade de objetos necessária para fazer pessoas, fatos ou objetos é, normalmente, difícil. Fatos, objetos ou pessoas requerem assistência para existir, e a existência é "maleável e mutuamente interativa", dependente do que está disponível (FUENTES, 2010, p.604). Assim, características, como raça, que tendem a ser estáveis em indivíduos nos Estados Unidos podem variar ao longo da vida das pessoas no Equador.

A frase nuestra realidad (nossa realidade), usada no cotidiano do Equador urbano, fala sobre os conjuntos particulares de relações contingenciais, conexões e restrições que moldam as especificidades da vida no país, algo que torna difícil aceitar uma realidade universal e singular. Nuestra realidad explicitamente designa a não universalidade. Algumas vezes ela se refere à falta de infraestrutura no Equador, por exemplo: "aquele projeto não funciona na nuestra realidad". Também escutei a frase ser usada de uma forma mais positiva, para denotar calor humano, apego e flexibilidade das pessoas na nuestra realidad em contraste com a dura individualidade nos Estados Unidos.

Nuestra reailidad se manifesta nas clinicas equatorianas de FIV regularmente. Co-ordenando os elementos de reprodução assistida que 
se acomodam suavemente na América do Norte é muito mais difícil em nuestra realidad. Médicos de FIV que voltam para casa de treinamentos no exterior, normalmente, encontram dificuldades em se ajustar ao ritmo mais lento e horários mais frouxos dos procedimentos nas clínicas, características da prática em locais com menos recursos. Enfermeiras que aguentam a ira de médicos cochicham entre si que tal médico não se ajustou à nuestra realidad. Esses mesmos médicos têm de ser lembrados de como foi difícil e oneroso conseguir suprimentos para essas clínicas. Quando eles demandam suprimentos para administradores desses locais, os administradores reclamam dizendo algo do tipo: "você pensa que é Natal e pode-se conseguir o que quiser por aqui?".

Nessas clínicas, nuestra realidad, envolvem-se contingentes materiais de relações que moldam organismos biológicos. Médicos de FIV moldaram seus regimes de medicamentos especificamente para os corpos de mulheres equatorianas que cresceram, geralmente, malnutridas e enfrentando a dura relação entre os problemas econômicos e burocráticos, como o alto custo de medicamentos importados para infertilidade e a dificuldade de transportá-los através das alfândegas. Algumas vezes, os profissionais têm de trocar os protocolos para se adequar ao que possuem ao seu alcance. Quando um micromanipulador de espermatozoides quebrou, o seu substituto levou um mês para chegar. Esse atraso fez com que Dr. Madera ${ }^{2}$ tivesse que descontinuar a injeção intracitoplasmática de esperma (ICSI), que era utilizada em quase todos os ciclos de FIV. Isso mudou como eram estimulados os ovários das mulheres. Uma série de circunstâncias que moldaram a realidade. Na mesma linha, pacientes experienciam seus corpos, não universalmente, mas individualmente. Como descreverei em seguida, pacientes mulheres de FIV ouviram que os hormônios da fertilidade causaram mudanças de humor em mulheres de outros países, mas eles atribuíam seus próprios sentimentos de tumulto emocional à complexidade e bagunça em lidar com suas vidas durante um processo difícil de projeto reprodutivo na nuestra realidad. Os desvios de protocolos internacionais feitos pelos médicos, bem como o senso dos pacientes sobre seus próprios corpos como sendo diferente dos corpos de outras mulheres, eram o resultado de configurações biológicas, econômicas

2 Todos os nomes utilizados neste artigo são pseudônimos. 
e institucionais específicas, entrelaçadas na nuestra realidad.

Nuestra realidad traz paralelos compreensivos com teóricos dos Estudos da Ciência e Tecnologia (STS) que, cuidadosamente, levam em conta as especificidades dos locais e da história, demonstrando que as tecnologias que são elaboradas para funcionar em todos os lugares, muitas vezes, não funcionam devido às diferentes circunstâncias materiais (DASTON, 1992; LATOUR, 1987). Por exemplo, fármacos que necessitam de refrigeração não funcionam bem em locais com eletricidade intermitente ou sem ela (CRANDON-MALAMUD, 1991). Objetos produzidos em laboratórios não são os mesmos em todos os lugares. Um embrião congelado em Délhi não é o mesmo que outro em Londres ou Quito. Eles são constituídos em relações materiais que os fazem diferentes. O que nuestra realidad nos permite é uma reflexão sobre as especificidades de como as coisas e pessoas vêm a ser e, por outro lado, como essas particularidades podem criar tipos de pessoas específicas. No Equador, a co-ordenação de coisas e pessoas, explicitamente, tem racializado-as.

Como em outras nações andinas, durante o século XIX e XX, as elites políticas e reformadoras sociais equatorianas estavam preocupadas com o que acreditavam ser um crescente "tribalismo" dos indígenas, algo que impedia o progresso e a coesão do Equador. Uma solução seria fazer nação mais clara/branca, cheia de cidadãos educados, através do processo de mestizaje (mestiçagem), por meio do encorajamento de filhos ilegítimos entre mulheres mais escuras e homens mais claros (HARRIS, 2008), e também tornando os índios mais claros através da educação, medicina e bem-estar social (CLARCK, 1998; DE LA CADENA, 2000). Enquanto o "vigor híbrido" da mítica raça mestiça tem sido celebrado em seus próprios termos, o projeto das elites tem sempre sido o de blanqueamiento (branqueamento) da nação através da mistura. Essa percepção de que há um problema racial e que é preciso um projeto para resolvê-lo ainda persiste. Em 1972, uma declaração afirmando que a mudança racial entre adultos era possível fez o presidente equatoriano, general Rodriguez Lara, proclamar: "o problema dos índios não existe mais. Nós todos nos tornamos brancos quando aceitamos os objetivos da cultura nacional" (STUTZMAN, 1981, p. 45).

Proponentes de programas racistas de mestizaje (mestiçagem) foram e são "otimistas raciais" ao invés de "pessimistas raciais", uma categoria mais comum no Oeste Europeu e na América do Norte. Esses últimos acreditavam possível impedir a reprodução de grupos indesejáveis (DE LA CADENA, 2000). Otimistas raciais não se esforçam para remover grupos por inteiro, 
optando por circunscrevê-los em uma "melhor" raça. Eles assumiram e ainda assumem uma característica maleável ao invés da intratabilidade da raça e da maleabilidade do efeito de melhoramento racial dentro de uma geração, até mesmo com indivíduos já existentes. Maleabilidade é uma premissa da raça como realidade material e da plasticidade dessa realidade que vem das contingências da vida cotidiana. A raça é cultivada e transformada através de circunstâncias materiais, como o vestir, a linguagem, a educação, a dieta e a ocupação. O processo histórico, econômico e político construído nesses atributos marca e faz o corpo das pessoas e suas realidades raciais (CLARK, 1998; DE LA CADENA, 2000; LEINAWEAVER, 2008; ORLOVE, 1998; PITT-RIVERS, 1973; SMITH, 1996; SWANSON, 2010; WADE, 1993; WEISMANTEL, 2001). Eu encontrei similares maleabilidades raciais em trabalho através da assistência - contribuições de tempo, dinheiro, e atenção corporal - envolvidos no tratamento médico das clínicas privadas de FIV no Equador. O tratamento médico é um dos meios de fazer pessoas racializadas, algo que está em relação direta com o projeto equatoriano de embranquecimento.

Indígenas, especialmente as mulheres indígenas supostamente superférteis, foram objeto dessas intervenções embranquecedoras do final do século XIX e começo do século XX por uma medicina financiada pelo Estado (CLARK, 1998; EWIG, 2000). Um século de negligência do Estado, produzindo uma infraestrutura de saúde em ruínas, mal suprida, com instituições de saúde públicas desenvolvidas para embranquecer sujeitos pobres e indígenas e incorporá-los em uma cidadania nacional, acaba por torná-los mais indígenas. Em outras palavras, pessoas que não têm recursos para pagar por serviços privados. O projeto de branqueamento nacional é facilitado pela negligência da medicina pública, que leva até mesmo pessoas com poucos recursos ao sistema privado. De fato, uma das grandes surpresas encontradas durante minha pesquisa foi o elevado número de pacientes da FIV com poucos recursos.

No começo dos anos 2000, os serviços estatais de saúde eram geralmente desvalorizados, buscados somente por pobres, indígenas ou afroequatorianos. Pessoas de várias classes e raças se endividavam para pagar serviços médicos privados, visando não ser tratados "como índios". Esta história racial e racista é essencial para entender como pacientes foram embranquecendo através da reprodução assistida em clínicas privadas no Equador.

Brancura é uma característica daqueles que utilizam clínicas privadas 
e podem evitar os cuidados abaixo da média da saúde pública na nuestra realidad. Também é uma característica de mulheres que sofrem especificamente de infertilidade. A partir do fim do século XIX, mulheres brancas das classes médias e altas em países emergentes da América Latina se tornaram responsáveis por melhorar o estoque racial de tais nações (ZULAWSKI, 2007). Esses programas reforçavam as distinções raciais entre, por um lado, mulheres indígenas extremamente férteis, que eram "conhecidas" por terem uma constituição física mais forte e, por isso, poderiam ter mais filhos sem assistência nos próprios campos onde trabalhavam, e por outro lado, mulheres brancas, que devido às suas capacidades reprodutivas delicadas requeriam maior assistência e proteção (DE LA CADENA, 2000; ICAZA, 1968).

Ao longo do século XX, a suposta superfecundidade de mulheres mais escuras e pobres as tornou objeto de um maior controle estatal, através de programas reprodutivos específicos (MORGAN; ROBERTS, 2012), enquanto a fecundidade de mulheres brancas foi gradativamente sendo vista como em risco. No Equador, encontrei uma predominante "infertilidade antecipatória" entre mulheres de classes médias e trabalhadoras. Entre as mulheres jovens, sem crianças e da classe média, quase todas tinham passado por alguma espécie de cirurgia (como a laparoscopia diagnóstica ou remoção de miomas) ou por um tratamento hormonal intensivo para corrigir uma função reprodutiva que deu errado. Essas mulheres estavam, com frequência, certas de que não poderiam ter filhos devido a algum estranho ou problemático sintoma menstrual. Considerando a construção histórica de mulheres brancas como sendo fertilmente frágeis, comecei a ver a disfunção reprodutiva como um meio para embranquecer, através de assistência privada e de recursos reservados aos mais desejados reprodutores equatorianos.

As mulheres e homens participando da reprodução assistida na nuestra relidad compartilhavam a percepção de que o mundo material e biológico era maleável, modificado através da configuração de pessoas e coisas, incluindo dinheiro e o cuidado que podem comprar. A frase "dinheiro embranquece" (el dinero blanquea) não é figurativa (LAU, 1998). Em relação à reprodução assistida, o dinheiro permite a participação na FIV, uma prática privada que serve ao projeto em andamento de branqueamento nacional através do embranquecimento de pacientes e crianças da FIV. Pacientes demonstram grande prazer em relatar quanto custou para produzir seus filhos através da reprodução assistida. O seu prazer é derivado da maneira pela qual, 
dentro das pesadas relações de hierarquia, desigualdade e instabilidade material, seus gastos os tornaram recipientes favoráveis da assistência de patronos poderosos: médicos privados da FIV e Deus. Pacientes não estavam necessariamente melhor após seus tratamentos, muitos estavam com dívidas enormes, mas eles tinham se tornado mais assistidos e brancos durante seus ciclos de FIV.

\section{Assistência Reprodutiva}

Escrevendo no início dos anos 1990, Marilyn Strathern afirmou que o parentesco euro-americano era baseado em um discreto sistema de indivíduos autônomos - no qual família, vida social e sociedade eram todos extrínsecos à pessoa, e a interdependência da pessoa a outros "parece ser negociável" (STRATHERN, 1992, p.25, ênfase da autora). Assim, a reprodução assistida, como toda reprodução, produz indivíduos. O que é problemático, no entanto, é que essas tecnologias introduzem um "novo contraste entre processos naturais e artificiais - a reprodução assistida transforma pais biológicos como uma categoria à parte... o que é novo é a assistência dada para domínios sociais e naturais." (STRATHERN, 1992, p.20). Esses contrastes não impediram que pessoas fizessem o uso dessas tecnologias, mas ansiedades sobre a artificialidade da ajuda da natureza foram consideradas ao tornar seu uso aceitável. Essas preocupações podem ser, de alguma forma, difundidas no trabalho de Charis Thompson, que escreve sobre clínicas de infertilidade nos Estados Unidos, a partir do termo "coreografia ontológica", que aponta "a agilidade de balancear a aproximação de coisas que geralmente são consideradas partes de diferentes ordens ontológicas (parte da natureza, parte do self, parte da sociedade)" (THOMPSON, 2005, p.8).

Os usuários da FIV na Califórnia que observei também tendem a coreografar o processo de tornar a assistência menos influente e encaixála num quadro de aceitabilidade de "fatos da vida", no qual reprodução é primariamente um processo biológico partilhado entre um homem e uma mulher, desconectado de tecnologia, dinheiro e relações com a família extensa, com o propósito de um filho próprio. Uma reclamação comum que ouvi de muitas mulheres casadas passando pela reprodução assistida era de que elas, e especialmente seus maridos, encontraram uma pressão exasperada e intromissão impertinente para com seu estado de ausência involuntária de filhos vinda de seus pais, irmãos, tios e tias. 
Essas reclamações enfatizam como um casal, idealmente, deveria fazer um filho. Através de práticas de gestação de substituição, outras práticas semelhantes eram acionadas. A tenacidade do corpo de uma gestora de substituição e as intervenções tecnológicas utilizadas para produzir uma gravidez desse tipo eram uma constante lembrança da "artificialidade" da assistência de que o casal necessitava para ter um filho. Em resposta, gestoras de substituição e casais iriam muitas vezes negar que a gestação era tecnológica e a naturalizavam através de explicações, tais como que essas práticas eram comuns em culturas "primitivas", percebendo-as como mais próximas da natureza. Algumas vezes, as pessoas descreviam práticas tecnológicas especificas como ultrassons, sincronia hormonal e parto induzido como conectores entre casais e gestoras de substituição. Esses momentos de conexão, no entanto, não diluíam maiores problemas da interferência tecnológica e da adição de terceiros ao projeto reprodutivo do casal.

Ao mesmo tempo, preocupações com a individualidade eram tão centrais para a construção do entendimento do que são pessoas que os participantes, algumas vezes, utilizavam a estrutura potencialmente alienável da reprodução assistida para enfatizar a individualidade de seus filhos ainda não nascidos. Uma mãe de classe média que contratou uma gestora substituta me disse:

"Desde que Tara nasceu eu sabia que ela não era parte de mim
geneticamente. Eu a via como um indivíduo. E eu tentei respeitar
que se ela não gosta de cenouras, quem se importa? Se ela
realmente tivesse vindo de mim, eu pensaria mais 'nós fazemos
isso desse jeito e você é uma de nós'. Mas ao invés disso eu preciso
me lembrar todo o tempo que Tara pode não ser como nós. Eu
acredito que o resultado disso é que ela é uma criança mais
determinada. E eu notei que outras crianças filhas de gestoras de
substituição também são".

A mãe de Tara poderia ter feito da criança "parte dela", ou "parte de nós", se focasse no cuidado que ela e outros membros da família deram para Tara após seu nascimento. Isso é o que muitas pessoas que encontrei no Equador fizeram em situações similares de adoção, gestação de substituição e doação de gametas. Eles usaram "sangue, genes e cuidado" para fazer e reforçar a conexão entre crianças e adultos (ROBERTS, 2012a, p.163). Ao invés disso, a mãe de Tara enfatizou como geneticamente, e 
por ser um bebê nascido através da gestação de substituição, Tara veio a existir mais autonomamente do que crianças nascidas através do ato sexual heterossexual.

Em contraste, a conexão, não a individualidade, inseriu a reprodução assistida no Equador urbano. Quando comecei minha pesquisa em Quito e Guayaquil, descobri que as intervenções tecnológicas da reprodução assistida não precisavam ser escondidas e que as conexões parentais para a criança eram frequentemente feitas em conjunto com outros. Especialmente em Quito, terceiros, como doadoras de óvulos, não eram necessariamente ameaçadores ou adições dolorosas para o processo, enquanto esses fossem membros da família. Em uma realidade improvável, em que era muito difícil imaginar que duas pessoas poderiam ter e criar uma criança sozinhos, era uma questão inevitável que uma multiplicidade de relações entre pessoas, objetos e processos tivesse que ser cultivada e co-ordenada para produzir filhos. Não tomamos essas relações como simples. Nas palavras de uma jovem mulher passando pela FIV, em meio a ministrações e cuidados sufocantes de suas relações: "Como sangre duele" (Como o sangue fere). Essas não eram relações inofensivas. Mas reprodução, em geral, e a FIV, em particular, tomam lugar dentro da família, e não através da moderna e transcendente "agência livre do peso de outras pessoas" (KEANE, 2006, p.310).

Profissionais e pacientes estavam de fato preocupados com o envolvimento das famílias na reprodução assistida. Havia uma dor quase paralisadora para lidar com a infertilidade, especialmente para mulheres, em sua existência centrada supostamente em criar crianças. Também havia grande investimento financeiro envolvido. Essas preocupações eram similares àquelas encontradas na Califórnia. Contudo, em uma realidade menos previsível como a do Equador, especialmente a de Quito, pacientes tendiam a ser muito mais ansiosos quanto a seus óvulos, esperma e embriões serem trocados ou misturados com os de outros pacientes. Uma preocupação mais rara na Califórnia. Gametas eram parentes, partes da família extensa, as únicas entidades potencialmente confiáveis. Perder gametas para estranhos constituía um abandono familiar, terrível para a existência assistida (ROBERTS, 2011). Usuários da FIV lutavam com o fato de serem católicos diante da condenação por parte da Igreja de todas as formas de reprodução assistida. Contudo, as suas preocupações não eram tão fortes como eu havia antecipado. Para os pacientes, a doutrina da Igreja era muito menos importante do que a negociação com Deus para Sua 
assistência no fazer crianças.

Neste terreno, em que as pessoas não se imaginavam sozinhas, a reprodução assistida enfatizava como crianças deveriam, idealmente, nascer antes de as técnicas terem mesmo chegado - com uma assistência abundante que reforçava as relações em meio à família extensa e, mais importante, com Deus. Usuários de FIV tomavam as conexões que a tecnologia propiciava com outros como muito vantajosa. Algumas vezes, parecia que, para pacientes, os bebês nascidos através da assistência de médicos, hormônios, cirurgias, doadores de gametas, e provetas existiam de uma forma "muito melhor" do que os bebês nascidos sem a ajuda dessas pessoas e coisas. Como demonstro na próxima sessão, as relações acionam e co-ordenam hormônios, repouso e doadores de gametas providos pela contribuição divina para a assistência e embranquecimento da existência.

\section{Assistência Divina}

Meu tempo de pesquisa entre usuários de FIV e gestação de substituição na região costeira da Califórnia foi, em sua maior parte, ausente de Deus. Esse não seria o caso se eu estivesse trabalhando em outra parte do país, até mesmo no Vale Central da Califórnia. Nos Estados Unidos, Deus está presente em grande parte da discussão nacional acerca do uso de reprodução assistida, especialmente a que envolve embriões. Desse modo, muitos pesquisadores da área da biotecnologia nos Estados Unidos perceberam que a religiosidade permeia a experiência das biotecnologias para muitos pacientes e suas famílias (LYERLY et al., 2008; RAPP, 1999; SHARP, 2006). No entanto, nas costas norte e sul da Califórnia, para todos os profissionais de saúde e vasta maioria de pacientes que encontrei, processos biológicos como a reprodução estavam separados da influência de Deus. Mesmo quando Deus era parte da vida desses sujeitos em outras esferas, e até mesmo quando eles experimentavam a reprodução assistida como "um milagre", Deus, como um ser espiritual, estava desconectado desse intenso processo biotécnico. As tecnologias de reprodução assistida não eram um domínio de Deus.

Quando iniciei minha pesquisa de campo no Equador urbano, não tomei o lugar de Deus seriamente, pensando que as imagens de referência católicas de Deus e da Virgem Maria penduradas nas clínicas de Quito serviam para "mostrar" ou acalmar os pacientes. Com o passar do tempo, acabei me dando conta de que Deus era parte integral do processo de 
FIV, tanto para os pacientes como para os profissionais de saúde. Para os médicos, embriologista e quase todos os pacientes e famílias de usuários de FIV que encontrei no Equador, as relações com Deus eram hierárquicas e paternalistas, diferentes das relações de obrigações mútuas estabelecidas entre parentes, amigos, crianças, médicos e enfermeiros. Deus estava sempre presente para ser chamado, nunca distante, impessoal ou burocrático. Enquanto a religiosidade era expressa de modo singular em cada cidade, a partir das realidades materiais das clínicas de reprodução assistida na América Latina, a maioria dos profissionais equatorianos da FIV que eu conheci insistia na sua dependência de Deus. Eles proclamavam que seus laboratórios eram de Deus e repetidamente lembravam-se e aos demais que eles necessitavam dessa assistência divina.

Em momentos-chave do processo de FIV, esses profissionais tocavam crucifixos nos incubadores de gametas e pediam a ajuda de Deus para com seus pacientes. Na clínica de Dr. Padilha em Quito, Linda, a bióloga responsável pelo laboratório, costumava beijar e acariciar a incubadora pedindo a Deus para fertilizar os óvulos. Ela frequentemente fazia uma curta oração, dirigindo-se muito amistosamente a Deus: "Que Diosito quiera que los ovulitos fertilicen" (Que Deusinho queira que os ovulozinhos sejam fertilizados). Em outro laboratório de Quito, Dra. Escobar costumava fazer o sinal da cruz antes de armazenar a placa de Petri com o óvulo e os espermatozoides na incubadora. Com os gametas seguros dentro da incubadora, ele os tocava gentilmente dizendo "Vayan con Dios" (Vão com Deus). Do outro lado da cidade, quando Dra. Leon terminava de combinar o óvulo e o esperma, ela tocava a imagem da Virgem Maria que estava pendurada acima do microscópio, fazendo o sinal da cruz. Quando ela fechava a porta da incubadora, após ter guardado a Placa de Petri, ela tocava o crucifixo que estava pendurado dentro de um saco plástico esterilizado e fazia mais uma vez o sinal da cruz. Pedir por intervenção divina dissolve a condenação do Vaticano à reprodução assistida. Rezas para a Virgem e trocas com Deus constituem a existência através da disciplina e rituais de autossacrifício, deixando claro para todos os presentes - profissionais e pacientes - que todo o poder sobre a vida está nas mãos de Deus. As repetidas invocações que presenciei envolviam a renovação da consciência sobre a presença de Deus através da prática (ver KIRSCH, 2004; ROBERTS, 2010). Durante os mais frágeis momentos do ciclo da FIV, quando a possibilidade de criação de um novo membro da família era duvidosa, profissionais e pacientes praticavam um tipo de serviço espiritual, lembrando a si mesmos 
e aos outros que eles não eram os responsáveis pela criação da vida. As repetidas checagem de temperatura na incubadora, onde os gametas eram armazenados, e as repetidas invocações a Deus acariciando um crucifixo junto à incubadora eram conclamações a uma direta assistência divina em busca do crescimento dos embriões.

Pacientes da FIV no Equador urbano também eram claros sobre a assistência que eles recebiam tanto da tecnologia quanto de Deus na sua busca por crianças. Os bebês da FIV eram, sem dúvida, tecnológicos e milagrosos. Como Hilda, uma paciente de Quito, me explicou: "Deus nos ajudou nisto...Toda a ciência é graças a ele. Se [pacientes] não têm filhos, não é porque eles não merecem, ou porque eles são más pessoas. É porque eles têm um destino que Deus quer. Sem a vontade de Deus nada existe". Quando perguntei a outro paciente sobre quantos embriões o médico tinha implantado, ela me corrigiu dizendo: "Não, você quer dizer transferiu, somente Deus decide sobre implantar". Uma mulher que tinha recebido óvulos de sua irmã explicou: "Deus e ciência são os mesmos". Como se para ilustrar esse ponto, sua irmã, a doadora, recontou vividamente o sonho que teve na noite prévia à doação: ela visualizou os embriões (clinicamente produzidos) nadando dentro do útero de sua irmã, com Deus guiando-os na implantação. Para a maioria dos profissionais e pacientes equatorianos da FIV, Deus manipula o mundo material em nome da continuidade familiar. Suas ações não rompem as leis da ciência, porque "toda ciência é [existe] graças a Ele". Intervenções divinas nos processos biológicos são reais, não são anormais ou sobrenaturais, e são consistentes com o modo como as pessoas e coisas precisam se juntar para moldar a reprodução assistida.

\section{Branqueamento Assistido}

Em uma nação na qual a disfunção reprodutiva feminina é uma marca de mulheres brancas, ter meios e métodos de tratá-la através da reprodução assistida também funciona para assistir ao branqueamento, a forma mais valiosa de ser no Equador. A FIV envolve uma vasta quantidade de intervenções privadas, sejam tecnológicas ou médicas, como cirurgias reprodutivas exploratórias, o paternalismo autoritário dos médicos, as quase inevitáveis cesarianas e doação de gametas, todas as quais enfatizam o privilegiado status de uma mulher que pode arcar com esse tipo de cuidado médico. Minhas conversas com essas mulheres eram cheias de histórias sobre seus medos com hospitais públicos, onde elas seriam 
deixadas "sozinhas" e tratadas "como índias ou mulheres negras", que eram tidas como reprodutoras naturais, sem a necessidade de muita assistência (ROBERTS, 2012b). Duas outras práticas - tratamentos hormonais e repouso - reforçavam a natureza cara e privada da assistência na FIV, as quais as pacientes recebiam para se tornar reprodutivas.

Durante os ciclos da FIV, hormônios, como o Lupron, eram administrados para regular e estimular a produção de folículos e aumentar a receptividade uterina. As pacientes californianas que entrevistei nos anos 90 descreviam seus regimes hormonais como algo que as fazia se sentir em uma montanha russa de emoções, ou como se elas fossem loucas. Isso era algo similar ao que outros cientistas sociais encontraram em relação aos hormônios de infertilidade nos Estados Unidos. Como uma mulher explicou para Gay Becker no seu estudo sobre a FIV:

“Lupron é como se tornar louca. Quando estou usando Lupron
eu fico nesta depressão agitada, realmente severa. Nunca me senti
tão suicida na minha vida... Você sabe em algum nível que são
só os químicos. Eu não estava esperando por isso, especialmente,
com a agitação além de tudo...Então, de tantas maneiras, o Lupron
é somente esta injeção em sua coxa, parece tão benigno. Mas não
é. A depressão aparece como uma resposta comum ao Lupron”.
(BECKER, 2000, p.88).

Essa mulher atribuía a instabilidade aos hormônios, como discretos, externos e não naturais agentes químicos que entram no corpo do indivíduo produzindo efeitos específicos, incluindo mudanças de humor (TEMKIN, 1977).

Talvez porque os efeitos desses hormônios eram tão centrais nas experiências das mulheres californianas, fiquei muito surpresa que a maioria das pacientes da FIV equatorianas não focavam suas falas neles, somente para dizer o quão caros eles eram. Elas normalmente atribuíam seus próprios sentimentos emocionais tumultuosos à complexidade e confusão que era lidar com suas próprias vidas durante o difícil projeto reprodutivo. Apesar de muitas pacientes descreverem sua irritabilidade, nervos e estresse durante os tratamentos da FIV, quando lhes perguntava se esses sentimentos eram devido aos hormônios, a resposta mais comum era um olhar vazio ou algo como a resposta de Roxana, que fazia o tratamento da FIV uma segunda vez: 
“Nada me afetava. Porque o médico me disse que isso poderia me deixar de mau humor. Mas pra mim não era isso. Eu tinha esse sentimento de que eu ia ficar grávida, que nada importava. Eu sofria um pouco com as injeções. Isso doía, sim, mas humores, não... Com todas as coisas juntas - faculdade, casa, marido sempre existem problemas".

Para a maioria dos pacientes de FIV no Equador, os tumultos emocionais que acompanham o processo eram atribuídos não a efeitos bioquímicos de uma discreta, externa ou de um agente artificial no corpo do indivíduo, mas às cambiantes dinâmicas familiares que se passavam em meio às demandas financeiras, físicas e existenciais da reprodução assistida.

Contudo, quando as mulheres experienciam efeitos de hormônios da fertilidade, elas normalmente os experimentam positivamente como uma ajuda ampliando sua fertilidade. Quando Sandra passou pela FIV (sem sucesso), ela se sentiu maravilhosa, "calma e linda graças aos hormônios". Sua pele estava macia, seus seios cheios. Algumas mulheres, inclusive, viam seus humores melhorando com os hormônios, uma paciente me falou: "eu me sentia como outra pessoa, melhor. Mais ativa e positiva", e outra paciente me explicou: "Meu caráter era mais dócil e calma, mais amável e cuidadoso". Para essas mulheres, hormônios eram uma (custosa) forma de assistência médica que contribuía para fazer seus corpos e comportamento reprodutivamente mais femininos.

Esse cuidado era um dos muitos componentes do processo da FIV que produzia e aprimorava a existência. No contexto do aprimoramento racial nos cuidados de infertilidade privados, a necessidade de hormônios custosos marcava os pacientes da FIV como mais brancos pela sua necessidade e pela sua habilidade de garantir essa assistência economicamente.

Após a transferência embrionária, pacientes da FIV e suas famílias precisavam esperar por duas semanas para realizar um teste de gravidez. O modo como uma paciente era acompanhada durante esse período de espera era visto como crucial para o sucesso das técnicas. Eu reconheci a importância desse cuidado quando Wilson, um jovem médico, retornou a trabalhar em uma clínica de Quito após um ano de treinamento em um centro de medicina avançada na Espanha. Antes disso, pacientes repousavam algumas horas deitados após a transferência de embriões, seguido de até duas semanas de repouso em casa até realizarem o teste de gravidez. Essa abordagem segue estudos recentes da América do Norte e Europa que mostram que o repouso em nada aumentava as taxas de 
gravidez. Wilson decide que as mulheres devem repousar por 15 minutos após a transferência e, em seguida, deixar a clínica. Eu o observei em várias ocasiões praticamente tirando seus pacientes das camas, recomendando que retornassem a suas vidas normais. Quase todos os pacientes se recusavam a escutar Wilson e se mantinham no que ele via como um comportamento desnecessário. A determinação "estrangeira" de Wilson em fazer os pacientes se levantar e sair aborrecia a percepção das mulheres em como deveriam agir e serem cuidadas nessas circunstâncias. "Ele achava que isso era um hospital público?". Enquanto esperavam em uma sala de recuperação, as mulheres enfatizavam seu estado frágil, pedindo para seus maridos ou parentes ajudá-las á ir ao banheiro. As enfermeiras, transtornadas com o novo protocolo de Wilson, sorrateiramente ofereciam comadres para as pacientes, enquanto se desculpavam pela sua aspereza.

$\mathrm{Na}$ maioria das outras clínicas de FIV nas quais realizei pesquisas, o protocolo pós-transferência embrionário enfatizava a assistência. No pequeno hospital ginecológico privado da Dra. Padilha, pacientes da FIV ficavam deitadas nas salas de transferência por até três horas após a transferência embrionária, e após isso permaneciam uma ou duas noites na clínica. A embriologista e a equipe da clínica as encorajavam a permanecer em suas camas em casa, deixando de trabalhar, se necessário. "Sem esforço físico. Nada além de repouso! Repouso! Repouso! Repouso! Repouso!”.

As pacientes que podiam permanecer em suas camas eram muito receptivas ao discurso de Linda. Suas instruções de repouso reconheciam a crucialidade do processo, dos esforços exercidos e do investimento financeiro que a família tinha despendido ao tentar fazer a criança. Com exceção de Wilson, os pacientes e profissionais em ambas as clínicas privadas trabalhavam para enfatizar todas as formas de assistência direcionadas às pacientes enquanto elas passavam pelo complicado processo de fertilização in vitro. Enquanto muitas das ferramentas e objetos necessários para realizar a FIV eram difíceis de conseguir, com o repouso aproveitava-se o que era de fato disponível no Equador: a reprodução assistida na forma de cuidados domésticos e o projeto familiar em uma coalizão encorajando uma mulher acamada a engravidar.

\section{Assistência de doadoras}

No oeste Europeu e na América do Norte, relações econômicas capitalistas e parentesco têm sido baseadas em uma divisão da intimidade em que 
mulheres, trabalho doméstico não remunerado e cuidado são separados do mercado masculino (SIMMEL, 1990 [1907]; WILSON, 2004). Essas divisões atualmente alimentam a maior parte das ansiedades acerca das tecnologias reprodutivas (AHUJA; SIMONS; EDWARDS, 1999; ROBERTSON, 2006). A possibilidade de que a mulher possa empregar sua intimidade reprodutiva potencial no mercado da venda de óvulos, por exemplo, faz ruir a separação entre parentesco e economia (GIMENEZ, 1991; RAGONÉ, 1994; STRATHERN, 1985). Não é surpreendente, então, que as doações pagas de óvulos tenham sido banidas em muitos países e o assunto debatido em muitos outros (STEINBROOK, 2006). Contudo, a venda de óvulos é permitida nos Estados Unidos (diferentemente do Reino Unido e de outras nações da Europa Ocidental), as transações são tratadas como doações de modo a coreografar o processo evitando a aparência de troca econômica. A maioria das doações de óvulos e gestoras de substituição que observei na Califórnia são enquadradas como presentes, mesmo quando o dinheiro troca de mãos - reformando o sentido de que "se a relação é íntima, ela não pode e não deve envolver trabalho, especialmente trabalho pago" (ZELIZER, 2010: 269; ver também ALMELING, 2011). Especialmente na Califórnia, o modelo do presentear é facilitado através da prática de que os pais de intenção conhecerão as doadoras, a quem eles podem presentear como também pagar.

A maior parte das pessoas que eu encontrei envolvidas na doação de gametas na Califórnia estavam ansiosas sobre a doação de gametas por uma série de razões. Quais eram as implicações genéticas de usar um óvulo ou esperma de estranhos? O que significava o dinheiro trocar de mãos? Se eles estivessem usando um membro da família "para saber" quem era o doador ou para evitar transações financeiras, como eles estabeleceriam a parentalidade primária do casal? No Equador, usar doadoras de gametas também poderia causar ansiedades, mas de uma forma diferente. A mistura racial era uma preocupação mais explícita e crucial, usar parentes femininos como doadoras era uma forma de assistência que muito raramente envolveria transações financeiras. Especialmente em Quito, a doação de óvulos não trazia uma nova ou inconfortável relação econômica e de parentesco. Ao invés disso, a prática era usada para reforçar uma assistência econômica mútua entre parentes.

Profissionais da reprodução assistida co-ordenavam ao mesmo tempo doações anônimas e não anônimas. Na tentativa de delimitar os limites da família nuclear heterossexual, esses profissionais em ambas as cidades em 
que pesquisei advogavam a favor da utilização de doações anônimas ao invés daquelas que utilizavam material genético de membros da família. Além disso, a doação anônima de óvulos ajudava a embranquecer a nação. Geralmente, médicos tentavam aproximar as doadoras de óvulo e esperma dos pacientes, o mais próximo possível. Esse processo envolvia uma variedade de fatores, incluindo, mas não se restringindo, à cor da pele. No entanto, frequentemente, era difícil encontrar uma doadora compatível, e então os profissionais da saúde escolhiam uma doadora mais clara que a receptora. Um biólogo explicou que eles procuravam doadores de uma "melhor classe social". Quando eu perguntei o que isso significava, ele me disse que o diretor da clínica não queria ter doadores indígenas. Ele queria mejorar la raza (melhorar a raça). As doadoras de óvulo que encontrei também foram explícitas acerca da sua contribuição para uma melhor raça, prevenindo famílias de receber uma criança mais escura através da adoção.

A doação anônima de óvulos parece ter maior apelo em Guayaquil, com sua história e trabalho individual monetizado. Em Quito, no entanto, pacientes tendem a não partilhar as dúvidas de seus médicos sobre a doação familiar. Eles querem evitar trocas com estranhos para além dos limites familiares, um sentimento claramente saturado com ansiedade racial. Vários pacientes em Quito me disseram que eles não gostariam de ter um doador anônimo por medo de receber óvulos "indígenas ou pretos". Além de prevenir uma indesejável mistura racial, a doação de óvulos entre mulheres aparentadas era experimentada como um modo de reforçar conexões familiares existentes através da troca de recursos materiais. Nos casos de doação familiar, a decisão de quem pedir para ser doadora envolve regras de parentalidade remanescentes da literatura antropológica sobre casamentos (BARTH, 1954; GOODY, 1959; LEACH, 1951). Ao invés de determinar com quem alguém pode casar para produzir um filho legítimo e criar alianças entre as famílias, as questões eram: quem pode doar óvulos? Quem melhor pode partilhar a experiência de ter filhos? E com quem eu gostaria de estreitar relações?

A doação entre irmãs, sobrinhas e tias, e entre mães e filhas servem não somente para trazer crianças ao mundo, mas também propiciam ocasiões para refletir sobre a manutenção de heranças e transferências de propriedades. Parte da antipatia dos pacientes em relação a pagar por uma doação anônima não estava no fato de o dinheiro trocar de mãos, mas no fato de o anonimato não permitir a continuidade da aliança material entre membros da família. Enquanto essas transações não eram oficialmente 
pagas, para as mulheres da família, elas quase nunca envolviam cálculos econômicos que incorriam em débito ou créditos. Várias das mulheres engajadas nessas transações estavam juntas no mercado, conjuntamente operando aventuras comerciais e descrevendo como a doação de óvulos de uma mulher jovem para uma mais velha pagava pelos débitos de ajuda nos negócios.

No Equador, pagamento, e não presente, era um idioma da doação de óvulos até mesmo entre membros da família. Quando eu perguntei a Lúcia se ela planejava dar dinheiro para sua irmã Ingrid para compensá-la pelo tempo que ela perdeu no trabalho quando ela estava doando óvulos, Ingrid interrompeu dizendo:

\footnotetext{
“Não. Eu mesma vou recuperar. Além disso, se Deus nos abençoar, você não tem que fazer nada. Seu bebê vai ser o melhor pagamento para todos nós. Para toda a família, quer dizer, para todos nós com todas essas incertezas nós queremos um pagamento. E esse pagamento vai ser isso [o bebê]. Nós poderemos então descansar, todos, complacentes e tranquilos".
}

Para muitos usuários de FIV de Quito, os óvulos de Ingrid não foram dados somente para Lúcia, mas serviram como pagamento para toda a família. Quando mulheres aparentadas e suas famílias mais amplas estão envolvidas, esclarecer a parentalidade era visto como uma tarefa administrável e não uma impossibilidade. De fato, as doadoras eram entendidas muito frequentemente como tendo estreitado relações com qualquer criança nascida através da sua doação, uma relação que não ameaçava a parentalidade da receptora dos óvulos, que assumia que a assistência familiar traria crianças à existência.

\section{Implicações da Assistência}

No Equador urbano do começo dos anos 2000, o tratamento de infertilidade privado envolvia cuidados enredados em formas de estratificação material e dominação, que existiam e se estendiam desde a era colonial até os anos neoliberais. Pacientes eram amplamente engajados em projetos normativos, como a formação de famílias heterossexuais em um terreno racista e hierárquico. Instituições estatais instáveis, serviços de bem-estar social erráticos e mesmo degradantes, e uma insegurança econômica crônica tornavam difícil co-ordenar pessoas e coisas. Médicos, biólogos, 
famílias e Deus eram mobilizados para fazer férteis o corpo de pacientes, juntando escassos recursos materiais com dinheiro, máquinas e hormônios. Assistência e não autonomia era a própria base da existência. Através da minha pesquisa etnográfica nessas clínicas privadas, comecei a entender dois desejados e interconectados aspectos da existência no Equador: interdependência e branqueamento. A cultivação desses dois elementos nos ajuda a explicar por que, apesar da chegada relativamente recente da FIV e da condenação dos procedimentos pela Igreja Católica, eles têm sido tomados com menos ansiedade no Equador em relação aos Estados Unidos. Práticas de reprodução assistida coincidem com os meios com que crianças e relações já são idealmente feitas em uma realidade material precária e hierárquica.

Adicionalmente, essas observações remodelaram meu entendimento de por que práticas experienciadas como auxiliares para indivíduos em locais com muitos recursos, como a Califórnia, poderiam causar tanta tensão existencial, notando como toda a assistência que é necessária em coordenar estabilizar pessoas e objetos pode ser difícil em locais com bastante recursos. Foi somente ao trabalhar no Equador que eu comecei a fazer um relato mais completo da assistência necessária para fazer medicina, ciência e tecnologia funcionar de uma forma geral e que diferentes formações ontológicas criam diferentes tipos de pessoas na Califórnia e no Equador. Minhas descobertas ressoam com o trabalho de acadêmicos da STS, que mostram como a realidade é feita não através de intrínsecas propriedades de pessoas e coisas, mas através de suas cambiantes inter-relações. Em outras palavras, a ontologia não é fixa, essa compreensão tem sido usada para fazer ruir essencialismos nocivos de raça, sexo e natureza (FAUSTOSTERLING 2000; HARAWAY 1991).

Meu estudo da reprodução assistida no Equador traz uma contribuição específica para os estudos da ciência e tecnologia ao demonstrar em um primeiro plano a política econômica da realidade, demonstrando, (1) que a vida em locais com menos recursos pode ter muito a ensinar em como a realidade é feita e, (2) que experenciar a realidade como algo sendo feito relacionalmente não é, necessariamente, liberador. Em relação ao primeiro ponto, em locais onde fazer pessoas e coisas é mais difícil de co-ordenar, uma descoberta acadêmica não é, necessariamente, notar a assistência necessária para a existência. A realidade é de fato experenciada como maleável porque a contingência envolvida no que une pessoas e coisas é palpável. Então, enquanto estudiosos do Norte global tendem a associar a maleabilidade 
corporal com elites, híbridos, e sujeitos neoliberais que podem se permitir participar das ofertas tecnológicas de ponta pra melhorar e modificar seus corpos (CHEN \& MOGLEN 2007; ROBERTS and SCHEPER-HUGHES 2011; TICKTIN 2011), eu percebi que no Equador, a maleabilidade corporal é parte da existência relacional diária através de classe e raça. A realidade maleável diária no Equador nos dá outros meios empíricos para entender que a estabilização da realidade não é igualmente distribuída. Uma sociedade altamente estratificada como os Estados Unidos que defende a igualdade, a vida e a individualidade, pode ser tomada como estável para uns e não para outros.

Em segundo lugar, minha análise da biotecnologia, em um contexto de maleabilidade racial e corporal como o do Equador, produz realizações preventivas para acadêmicos da STS que procuram problematizar divisões determinísticas de natureza/cultura visando desfazer estratificações de raça e sexo. Existência assistida no Equador ilumina, derrubando determinismos de natureza/cultura que não, necessariamente, desmontam hierarquias, fazendo a economia política essencial para o estudo de processos biocientíficos do corpo. Em outras palavras, raça fluída e maleável pode ser tão perigosa como a regra da "uma gota" ${ }^{3}$. Focando nas relações de recursos para ser, tanto em relação à reprodução assistida, e mais geralmente em como as pessoas vem a existir, pode trazer questões comparativas, como: em diferentes lugares, quais objetos são estáveis e como eles se tornaram assim? Qual tipo de assistência e quais tipos de autonomia são desejados? Por quem e como? Quais configurações materiais produzem quais tipos de pessoas?

Focar especificamente na assistência assistida me permitiu investigar as condições específicas que fazem pessoas produzidas pela FIV virem a existir, e os tios de assistência que essas pessoas receberam quando nascerem. Na Califórnia, como no Equador, bebês de gestoras substitutas e FIV foram feitos na esfera privada e com grande custo. Possivelmente ainda mais do que no Equador, bebês nascidos através da reprodução assistida na Califórnia, geralmente nasceriam em uma relativa abundância material, os distinguindo de outras crianças que os pais não poderiam pagar por

\footnotetext{
${ }^{3}$ A regra "uma gota" é um termo utilizado nos Estados Unidos para fazer referência a uma lei do século XX em alguns estados do Sul que classificava qualquer pessoa com "uma gota de sangue negro" como preta.
} 
esse tipo de assistência. Além disso, assistência tecnológica privada em conjunção com uma abundância de recursos providos pelo Estado fazem a vida dos bebês parecerem mais autônomas e menos dependentes de assistência. Se esse é o caso, pode ser que esta tecnologia e esses recursos também contribuam para fazer bebês e pais mais brancos na Califórnia, como no Equador? Mesmo se a reprodução assistida contribua para fazer raça na Califórnia, diferenças entre a existência nessas duas nações é enorme. Tanto no Equador, quanto na Califórnia, as infraestruturas do estado que beneficiam as elites eram ocultas, mas a política e história econômica dessas nações eram feitas para diferentes pessoas. Na Califórnia, era desejável assegurar autonomia, diferente do Equador, aonde receber assistência nunca era demais.

\section{Notas}

Matthew Engelke, Matt Hull, Erik Mueggler, Aaron Seaman, Harris Solomon, Janelle Taylor, Ara Wilson, Kate Zaloom e três avaliadores anônimos da JRAI me ofereceram comentários incisivos e criticaram esse manuscrito deixando claro que minha vida intelectual sempre existe através de outros.

Texto traduzido por Débora Allebrandt e Felipe Benedet Maureira.

\section{Referências}

AHUJA, K.K., E.G. SIMONS \& R.G. EDWARDS.

(1999). Money, morals and medical risks: conflicting notions underlying the recruitment of egg donors. Human Reproduction 14, 27984.

ALMELING, R.

(2011). Sex cells: the medical market for eggs and sperm. Berkeley, University of California Press.

BARTH, F.

(1954). Father's Brother's Daughter marriage in Kurdistan. Southwestern Journal of Anthropology 10, 164-71.

BECK, S., M. KLOTZ \& M. KNECHT.

(2012). Reproductive technologies as global form: ethnographies of knowledge,practices, and transnational encounters. Frankfurt, Campus.

BECKER, G.

(2000). The elusive embryo: how women and men approach new reproductive technologies. Berkeley, University of California Press.

BHARADWAJ, A.

(2002). Conception politics: medical egos, media spotlights, and the contest over testtubefirsts in India. In: M. Inhorn \& F.V. Balen (Eds.); Infertility around the globe. Berkeley, University ofCalifornia Press.

CALLON, M.

(1989). Some elements of a sociology of translation: domestication of the scallops and the fishermen of St Brieuc Bay. In: J. 
Law (Ed.); Power, action and belief. London, Routledge.

CHEN, N.N. \& H. MOGLEN.

(2007). Bodies in the making: transgressions and transformations. Santa Cruz, Calif / New Pacific Press.

CLARK, K.A.

(2002). The language of intention in liberal Ecuador. In: W. Lem \& B. Leach (Eds); Culture, economy, power: anthropology as critique, anthropology as praxis. Albany, State University of New York Press.

(1998). Race, 'culture', and mestizaje: the statistical construction of the Ecuadorian nation, 1930-1950. Journal of Historical Sociology, 11, p. 185-211.

CLARK, K.A.; BECKER, M.

(2007). Highland Indians and the state in modern Ecuador. Pittsburgh, University Press.

CLARKE, A.; J.H. FUJIMURA.

(1992). The right tools for the job: at work in twentieth-century life sciences. Princeton, University Press.

\section{CLARKE, M.}

(2009). Islam and new kinship: reproductive technology and the shariah in Lebanon. New York, Berghahn.

CRANDON-MALAMUD, L.

(1991). From the fat of our souls: social change, political process, and medical pluralism in Bolivia. Berkeley, University of California Press.

DASTON, L.

(1992). Objectivity and the escape from perspective. In: M. Biagioli (ed.); The science studies reader. New York, Routledge.

DE LA CADENA, M.

(2000). Indigenous mestizos: the politics of race and culture in Cuzco, Peru, 1919-1991. Durham, N.C., Duke University Press.
DE LAET, M.; A. MOL.

(2000). The Zimbabwe bush pump: mechanics of a fluid technology. Social Studies of Science 30, p.225-63.

EWIG, C.

(2010). Second-wave neoliberalism: gender, race, and health sector reform in Peru. University Park, Pennsylvania State University Press.

FAUSTO-STERLING, A.

(2000). Sexing the body: gender politics and the construction of sexuality. New York, Basic Books.

FRANKLIN, S. \& C. ROBERTS.

(2001). The social life of the embryo. Paper presented at Ethnographies of the Centre, Lancaster University, in 10 September. Available on-line: http://www.lancs.ac.uk/ fass/sociology/research/publications/ papers/roberts-franklin-social-life-ofembryo.pdf. Last access: May 20th 2013.

FUENTES, A.

(2010). Natural cultural encounters in Bali: monkeys, temples, tourists, and ethnoprimatology. Cultural Anthropology, 25, p.600-24.

GERLACH, A.

(2003). Indians, oil, and politics: a recent history of Ecuador. Wilmington, De., Scholarly Resources.

GIMENEZ, M.E.

(1991). The mode of reproduction in transition: a Marxist-feminist analysis of the effects of reproductive technologies. Gender and Society, 5, p.334-50.

GOODY, J.

(1959). The Mother's Brother and the Sister's Son inWest Africa. Journal of the Royal Anthropolgical Institute, 89, p.61-88.

HANDWERKER, L.

(1995). The hen that can't lay an egg: conceptions of female infertility in modern China. In: J. Terry \& J. Urla (Eds.); Deviant bodies. Bloomington, University of Indiana Press. 
HARAWAY, D.J.

(2008). When species meet. Minneapolis, University of Minnesota Press.

(1991). Simians, cyborgs and women: the reinvention of nature. London, Free Association Books.

HARRIS, 0.

(2008). Alterities: kinship and gender. In: D. Poole (Ed.); A companion to Latin American anthropology. p.276-302. 0xford, Blackwell.

ICAZA, J.

(1968). Huasipungo: novela. Buenos Aires, Losada.

INHORN, M.C.

(2003). Local babies, global science: gender, religion, and in vitro fertilization in Egypt. New York, Routledge.

IVRY, T.

(2009). The ultrasonic picture show and the politics of threatened life.Medical Anthropology Quarterly, 23, p.189-211.

KEANE, W.

(2006). Anxious transcendence. In: F. Cannell (

Ed.); The anthropology of Christianity. Durham,

N.C., Duke University Press.

\section{$\mathrm{KIRSCH}, \mathrm{T}$.}

(2004). Restaging the will to believe: religious pluralism, anti-syncretism, and the problem of belief. American Anthropologist 106, p.699709.

KOSEK, J.

(2010). Ecologies of empire: on the new uses of the honeybee. Cultural Anthropology 25, p.650-78.

LATOUR, B.

(2010). On the modern cult of the factish gods. Durham, N.C.: Duke University Press.

(1987). Science in action: how to follow scientists and engineers through society. Cambridge, Mass., Harvard University Press.
LAU, E.T.

(1998). Can money whiten? Exploring race practice in colonial Venezuela and its implications for contemporary race discourse. Michigan Journal of Race and Law 3, p.417-73.

LEACH, E.

(1951). The structural implications of matrilateral cross-cousin marriage. Journal of the Royal Anthropological Institute, 81, p.23-53.

\section{LEINAWEAVER, J.B.}

(2008). The circulation of children: kinship, adoption, and morality in Andean Peru. Durham, N.C., Duke University Press.

LOCK, M.M.

(1993). Encounters with aging: mythologies of menopause in Japan and North America. Berkeley, University of California Press.

LYERLY, A.D.; STEINHAUSER, K.; VOILS, C.; NAMEY, E.; ALEXANDER, C.; BANKOWSKI, B.; et al.

(2008). Fertility patients' views about frozen embryo disposition: results of a multiinstitutional U.S. survey. Fertility and Sterility, 93, p.499-509.

MOL, A.

(2002). The body multiple: ontology in medical practice. Durham, N.C., Duke University Press.

MOORE, D.S.; KOSEK, J.; PANDIAN, A.

(2003). Race, nature, and the politics of difference. Durham, N.C., Duke University Press.

MORGAN, L.; ROBERTS, E.F.S.

(2012). Reproductive governance in Latin America. Anthropology and Medicine, 19, p.241-54.

NAHMAN, M.

(2008). Synecdochic ricochets: biosocialities in a Jerusalem IVF clinic. In: S. Gibbon \& C. Novas (Eds); Biosocialities, genetics and the social sciences: making biologies and identities. p.117-35. London, Routledge. 
ORLOVE, B.

(1998). Down to earth: race and substance in the Andes. Bulletin of Latin American Research 17, p.207-22.

PASHIGIAN, $M$.

(2009). Inappropriate relations: the ban on surrogacy with in vitro fertilization and the limits of state renovation in contemporary Vietnam. In: D. Birenbaum-Carmeli \& M.C. Inhorn (Eds.); Assisting reproduction, testing genes: global encounters with new biotechnologies. New York, Berghahn. p.16488

PITT-RIVERS, J.

(1973). Race in Latin America: the concept of raza. Archives Européennes de Sociologie XIV, p.3-31.

RABINOW, P.

(1996). Artificiality and enlightenment: from sociobiology to biosociality. In: P. Rabinow (Ed.); Essays on the anthropology of reason. Princeton, University Press. p.91-111.

RAGONÉ, H.

(1994). Surrogate motherhood: conception in the heart. Boulder, Colo., Westview.

RAPP, R.

(1999). Testing women, testing the fetus: the social impact of amniocentesis in America. New York, Routledge.

ROBERTS, E.F.S.

(2012b). Scars of nation: surgical penetration and the Ecuadorian state. Journal of Latin American and Carribean Anthropology, 17, p.215-37.

(2012a).God's laboratory: assisted reproduction in the Andes. Berkeley, University of California Press.

(2011). Abandonment and accumulation: embryonic futures in the United States and Ecuador. Medical Anthropology Quarterly 25, p.232-53.

(2010). Ritual humility in modern laboratories: or, why Ecuadorian IVF practitioners pray. In: W.S. Sax, J. Quack \& J. Weinhold (Eds.); The problem of ritual efficacy. 0xford; University Press.

(1998). 'Native' narratives of connectedness: surrogate motherhood and technology. In: J. Dumit \& R. Davis-Floyd (Eds.); Cyborg babies: from techno-sex to techno-tots. New York, Routledge.

ROBERTS, E.F.S.; N. SCHEPER-HUGHES.

(2011). Medical migrations. Body and Society, 17, 2-3, p.1-30.

ROBERTSON, J.A.

(2006). Compensation and egg donation for research. Fertility and Sterility, 86, p.1573-5.

SHARP, L.A.

(2006). Strange harvest: organ transplants, denatured bodies, and the transformed self. Berkeley, University of California Press.

SIMMEL, G.

(1990 [1907]). The philosophy of money (trans.

D. Frisby). New York, Routledge.

SMITH, C.A.

(1996). Myths, intellectuals, and race/class/ gender distinctions in the formation of Latin Americannations. Journal of Latin American Anthropology, 2, p.148-69.

STEINBROOK, R.

(2006). Egg donation and human embryonic stem cell research. New England Journal of Medicine 354, p.324-6.

STRATHERN, $M$.

(2005). Kinship, law and the unexpected: relatives are always a surprise. Cambridge, University Press.

(1992). Reproducing the future: essays on anthropology, kinship, and the new reproductive technologies. New York, Routledge.

(1985). Kinship and economy: constitutive orders of a provisional kind. Ethnologist 12, p.191-209. 
STUTZMAN, R.

(1981). El mestizaje: an all-inclusive ideology. In: N. Whitten (Ed.); Cultural transformations and ethnicity in modern Ecuador. Urbana, University of Illinois Press.

\section{SWANSON, K.}

(2010). Begging as a path to progress: indigenous women and children and the struggle for Ecuador's urban spaces. Athens, University of Georgia Press.

TEMKIN, 0.

(1977). The double face of Janus and other essays in the history of medicine. Baltimore, Md, Johns Hopkins University Press.

THOMPSON, C.

(2005). Making parents: the ontological choreography of reproductive technologies. Cambridge, Mass., MIT Press.

TICKTIN, M.

(2011). How biology travels: a humanitarian trip. Body and Society, 17, 139-58.
WADE, P.

(1993). Race, nature and culture. Man (N.S.), 28, 17-34.

\section{WEISMANTEL, M.J.}

(2001). Cholas and pishtacos: stories of race and sex in the Andes. Chicago, University Press.

WILSON, A.

(2004). The intimate economies of Bangkok: tomboys, tycoons, and Avon ladies in the global city. Berkeley, University of California Press.

ZELIZER, V.

(2010). Caring everywhere. In: E.Boris \& R.S. Parreñas (Eds.); Intimate labors: cultures, technologies, and the politics of care. Stanford, University Press.

ZULAWSKI, A.

(2007). Unequal cures: public health and political change in Bolivia, 1900-1950. Durham, N.C., Duke University Press. 